\title{
Geoepidemiology and changing mortality in primary biliary cholangitis
}

\author{
Annarosa Floreani $^{1} \cdot$ Atsushi Tanaka $^{2} \cdot$ Christopher Bowlus $^{3} \cdot$ Merrill Eric Gershwin $^{4}$
}

Received: 15 March 2017/Accepted: 16 March 2017/Published online: 1 April 2017

(c) Japanese Society of Gastroenterology 2017

\begin{abstract}
Primary biliary cholangitis (PBC), formerly called primary biliary cirrhosis, is a chronic cholestatic disease characterized by an autoimmune-mediated destruction of small and medium-sized intrahepatic bile ducts. Originally $\mathrm{PBC}$ was considered to be rare and almost invariably fatal, mainly because the diagnosis was made in patients presenting with advanced symptomatic disease (jaundice and decompensated cirrhosis). However, the development of a reproducible indirect immunofluorescence assay for antimitochondrial antibody made it possible to diagnose the disease at an earlier stage, and introduction of ursodeoxycholic acid therapy as the first-line therapy for PBC drastically changed PBC-related mortality. At present, patients with an early histological stage have survival rates similar to those of an age- and sex-matched control population. Although $30 \%$ of patients treated with ursodeoxycholic acid may exhibit incomplete responses, obeticholic acid and drugs currently in development are expected to be effective for these patients and improve outcomes. Meanwhile, more etiology and immunopathology studies using
\end{abstract}

Part of this review was presented at Japan Digestive Disease Week 2016.

Merrill Eric Gershwin

megershwin@ucdavis.edu

1 Department of Surgery, Oncology and Gastroenterology, University of Padova, via Giustiniani, 2, Padova, Italy

2 Department of Medicine, Teikyo University School of Medicine, Tokyo, Japan

3 Division of Gastroenterology and Hepatology, School of Medicine, University of California, Davis, Davis, CA, USA

4 Division of Rheumatology, Allergy, and Clinical Immunology, School of Medicine, University of California, Davis, Davis, CA, USA new technologies and novel animal models are needed to dissect variances of clinical course, treatment response, and outcome in each patient with PBC. Precision medicine that is individualized for each patient on the basis of the cause identified is eagerly awaited.

Keywords Ursodeoxycholic acid - Obeticholic acid . Cirrhosis $\cdot$ Etiology $\cdot$ Precision medicine

\section{Introduction}

Primary biliary cholangitis (PBC), formerly called primary biliary cirrhosis, is a chronic cholestatic liver disease, of autoimmune origin, predominantly affecting middle-aged women and that may progress to end-stage liver disease [1]. The first description was reported by Addison and Gull [2] in 1857 in a 42-year-old women who reported having had "jaundice for 2 years and patches of a light opaque color in the surface of eyelids; after 4 years from the beginning of jaundice the general surface deepened to a mahogany brown." Originally PBC was considered to be rare and almost invariably fatal $[3,4]$. This was mainly because the diagnosis was made in patients presenting with advanced symptomatic disease (jaundice and decompensated cirrhosis). However, the development of a reproducible indirect immunofluorescence assay for antimitochondrial antibody introduced the modern diagnosis of PBC and the concept of asymptomatic disease [5]. The application of antimitochondrial antibody in clinical practice also made the diagnosis of PBC much easier, resulting in alteration of epidemiological data through an increase in the number of patients with PBC. Furthermore, the introduction of ursodeoxycholic acid (UDCA) therapy as the first-line therapy for PBC [6] drastically changed 
Table 1 Incidence and prevalence of primary biliary cholangitis in study populations reported after 2000

\begin{tabular}{|c|c|c|c|c|c|}
\hline Authors & Country & Period & Incidence per million & Prevalence per million & Method \\
\hline Baldursdottir et al. [16] & Iceland & 1991-2010 & $0.24-0.34$ & 3.83 & Case finding \\
\hline Pla et al. [18] & Spain & 1990-2002 & 17.2 & 195 & Case finding \\
\hline Myers et al. [17] & Canada & 1996-2002 & 30.3 & $100-227$ & Population-based \\
\hline Delgado et al. [73] & Israel & 1990-2010 & $10-20$ & 255 & Case finding \\
\hline
\end{tabular}

PBC-related mortality, and another therapeutic option, obeticholic acid (OCA), was recently provided for patients with incomplete response to UDCA [7] and is expected to further reduce mortality for patients with $\mathrm{PBC}$. In this review, we briefly outline the geoepidemiology of $\mathrm{PBC}$ and also the great reduction in PBC-related mortality as a result of improved treatments, especially by the introduction of UDCA therapy.

\section{Geoepidemiology}

To date, data on the systematic epidemiology of PBC are uncertain, because of the lack of a proper epidemiological design. The first study on the epidemiology of PBC was performed in 1974 by Hamlyn and Sherlock [8], who examined 165 death certificates collected in England and Wales over the 5-year period from 1967 to 1971. This corresponds to a crude rate of 1.2 million per year for females or 0.6 million per year for both sexes [8]. The new era for studying the epidemiology of PBC began in 1990 with the lesson from Newcastle in the UK [9]. In a welldefined region with a population of 1.92 million, case records of patients who received a diagnosis of PBC during hospital admissions from 1965 to 1987 were reviewed, with use of data from regional hospital disease analysis of 16 hospitals. Prevalence rose from 18 per million in 1976 to 128.5 per million in 1987 and 871 per million in 1994 [9]. Incidence rose from 11.3 per million in 1976 to 19.8 per million in 1987 and 61 per million in 1994. These figures raise several questions about the specific epidemiology of PBC in the Newcastle region; in particular, they give the impression that the mortality data for PBC greatly underestimated this disease as a cause of death. Subsequently, two further epidemiological studies from the Newcastle area were published $[10,11]$. These studies used multiple case-finding strategies to identify a comprehensive cohort of patients with PBC, including those in primary care and those in whom the diagnosis was based after prior investigations. The incidence of PBC rose from 23 per million in 1987 to 32.2 per million in 1994 (91.3-100 per million in women older than 40 years). A study conducted in Australia [12] was repeated in 2002 in the same population [13]; a prevalence of 51 cases per million was found, a rate that was significantly higher than before, due to large migrant ethnic groups, but the age-adjusted prevalence in those born in Victoria remained significantly lower than in the UK and less than in migrant communities. Overall, epidemiological data have shown a trend toward an increasing age of presentation of the disease. In an Italian study, the age at diagnosis for representative calendar years (from 1973 to 2007) increased gradually from $47.7 \pm 1.5$ years to $63.6 \pm 2.9$ years, with statistical significance [14]. Moreover, the proportion of patients asymptomatic at diagnosis increased from $25 \%$ between 1973 and 1980 to $46 \%$ in the last decade [14]. In a large cohort of asymptomatic patients in the Newcastle area, the median age at presentation was 63.1 years, which is comparable with more recent figures from Italy [15]. In more recent years, both incidence and prevalence higher than before have been reported (Table 1) [16-18].

\section{The natural history of $\mathrm{PBC}$ in terms of symptoms}

Table 2 summarizes the most important studies regarding the natural history of PBC, including asymptomatic and symptomatic patients. The presentation of the disease has been changed over time, and there is a bias in older studies regarding the distinction between asymptomatic and asymptomatic patients. The oldest study was performed in the USA with a follow-up of 12.1 years [19]. The median predicted survival of asymptomatic patients was 16 years versus 7.5 years in symptomatic patients $(p<0.0001)$. In asymptomatic patients, survival was shorter than that predicted for an age- and sex-matched control population, a difference that became apparent only after 11 years of follow-up. Patients who present with asymptomatic disease have been shown to have a shorter survival in icomparison with the general population by two additional studies [20-22].

In the pre-UDCA era, the symptom in patients with PBC was mainly jaundice, which reflected progression of the disease. As a result, patients with asymptomatic disease tended to have a more benign course than symptomatic patients [23, 24]. However, since detection of PBC at earlier stages has been possible with diagnostic tools such as antimitochondrial antibody, patients with PBC are often asymptomatic at diagnosis, and the symptoms found in 
Table 2 Natural history of primary biliary cholangitis in asymptomatic and symptomatic patients

\begin{tabular}{|c|c|c|c|c|c|c|}
\hline Authors & Country & Peiod & $\begin{array}{l}\text { Survival among asymptomatic } \\
\text { patients (years) }\end{array}$ & $\begin{array}{l}\text { Survival among symptomatic } \\
\text { patients (years) }\end{array}$ & $p$ & Follow-up \\
\hline Mahl et al. [74] & USA & 1955-1979 & 16 & 7.5 & 0.0001 & 12.1 years \\
\hline Balasubramaniam et al. [20] & USA & 1974-1984 & 73 & & & 7.6 years \\
\hline Springer et al. [75] & Canada & 1983-1994 & 14 & & & 61.2 months \\
\hline Prince et al. [76] & UK & 1996-2002 & 9.6 & 8.0 & NS & 7.4 years \\
\hline Nyberg and Loof [21] & Sweden & & 12.7 & 8.0 & & 9.0 years \\
\hline Roll et al. [24] & USA & & - & 11.9 & & 6.9 years \\
\hline Beswick et al. [23] & USA & & 14 & & & 11.4 years \\
\hline
\end{tabular}

$N S$ not significant

patients with PBC are not necessarily related to disease progression. The prevalent symptoms among PBC patients are currently not jaundice, but fatigue or pruritus, both of which are not associated with disease severity and can be found even in earlier stages. In the UDCA era, a large community-based study from Newcastle demonstrated that the median survival was similar in asymptomatic and symptomatic groups: 9.62years versus 8.0 years respectively [15]. This intriguing result was not analyzed in detail but has been supposed to be due to less severity in symptomatic patients (only $32 \%$ cirrhotic) and an excess of nonhepatic deaths, particularly in the asymptomatic group.

\section{Changing mortality with improved treatment}

\section{Ursodeoxycholic acid}

The natural history was greatly changed in the UDCA era [25]. Extended data from several studies indicate that UDCA improves the natural history of PBC, especially when UDCA is administered in early stages [26-28]. With use of a multistate modeling approach to assess the effect of UDCA on the course of PBC, it was found that the survival rate of patients with stage I and stage II disease was similar to the survival rate of an age- and sex-matched control population, whereas the probability of death or orthotropic liver transplant remained significantly increased in UDCA-treated patients with late histological stage disease [26]. Although a meta-analysis of 16 randomized clinical trials including 11,447 patients failed to demonstrate any beneficial effect of UDCA with regard to reducing mortality and mortality or liver transplant rates [29], evidence suggests that UDCA delays histological progression of $\mathrm{PBC}$ and decreases the risk of development of esophageal varices; moreover, survival of UDCA-treated patients is better than that of untreated patients [30].

Stratification of the risk of progression and death has been performed in patients treated with UDCA. The Global
PBC Study Group, which includes 15 liver centers from eight North American and European countries, performed a meta-analysis of 4119 patients with PBC treated with UDCA [31]. A prognostic score (GLOBE score) to predict transplant-free survival was developed and validated with use of clinical and laboratory variables at 1 year after commencement of UDCA treatment. An overall threshold was determined for the GLOBE score: patients with a GLOBE score greater than 0.30 had diminished survival compared with a matched general population. The GLOBE score improved identification of patients who did not responder to UDCA treatment in comparison with previously reported criteria [27]. Recently, another long-term prognostic model of PBC has been developed, from the UK PBC derivation cohort of 1916 UDCA-treated patients [32]. The authors also validated the risk scores in an independent cohort of 1249 UDCA-treated participants. In the validation cohort, the 5-, 10-, and 15-year risk scores were highly accurate (area under the curve greater than 0.90). Thus, the utility of both the GLOBE score and UK score is to assign a provisional prognostic risk to a UDCAtreated patient with PBC. A limitation of the new scores is that the evaluation of a single patient requires at least 12 months of UDCA therapy. However, they provide an encouraging risk assessment of patients with PBC.

\section{Obeticholic acid}

There is a subpopulation of patients who exhibit an incomplete response to UDCA and another therapeutic option has been long awaited. In 2016, a new drug, OCA, was officially approved for treatment of patients with PBC who are intolerant of or refractory to UDCA.

Estimation of OCA long-term clinical impact and costeffectiveness has been assessed with a microsimulation model in an adult population with inadequate response to UDCA with reference to the titration arm of POISE [33]. This model was validated with 15 -year transplant-free survival data from the Global PBC Study. The addition of 
OCA therapy to UDCA therapy in PBC patients would decrease the 15-year cumulative incidence of liver-related deaths from $27 \%$ to $11 \%$, the cumulative incidence of decompensated cirrhosis from $5 \%$ to $2 \%$, the cumulative incidence of hepatocellular carcinoma (HCC) from $4 \%$ to $2 \%$, and the cumulative incidence of liver transplant from $0.6 \%$ to $0.2 \%$. OCA treatment would also increase the 15 -year transplant-free survival rate from $60 \%$ to $72 \%$ [33]. These data suggest that the use of OCA is expected to improve the long-term outcome in PBC patients.

\section{Transplant}

A recent article compared the $\mathrm{PBC}$ waiting list outcomes with those of hepatitis $\mathrm{C}$ virus (HCV) infection and alcoholic liver disease (ALD) waiting list candidates using the United Network for Organ Sharing during the period from 2000 to 2014 [34]. There were 5472 liver transplant candidates with PBC, 54,043 with HCV infection, and 25,570 with ALD. When the probability of receiving a liver transplant was evaluated for the three conditions, PBC patients showed the largest decline $(13.5 \%$ vs $7.5 \%$ for HCV patients and $6 \%$ for ALD patients, $p<0.05$ ). PBC patients experienced the largest decline in waiting list survival $(p<0.05)$. In multivariate analysis, malnourished PBC patients with low albumin levels were at the highest risk of dying while on the waiting list. However, PBC patients listed for liver transplant have higher waiting list mortality than patients with other disease (primary sclerosing cholangitis, HCV infection, and ALD) except for those listed for combined HCV infection and ALD [35]. These findings suggest that patients with $\mathrm{PBC}$ listed for liver transplant may be evaluated when their Model for End-Stage Liver Disease score is lower than that indicated for end-stage liver disease.

\section{Causes of death}

Three European studies including large cohorts of PBC patients analyzed the causes of death during mean followups of 7.4, 4.8, and 6 years respectively [14, 15, 36] (Table 3). The three cohorts were similar for length of follow-up and female-to-male ratio, but there was a discrepancy regarding the causes of death. Most patients in the Italian cohort died of liver failure, whereas there was a liver-related cause in $36.1 \%$ of patients in the UK and $34.4 \%$ of patients in the Netherlands. There are several reasons for the excessive mortality due to unrelated liver disease, including comorbidities with or without autoimmunity, heavy smoking, or nonhepatic malignancies. Two studies, however, failed to demonstrate a direct effect on mortality in PBC for both extrahepatic autoimmunity and
Table 3 Causes of death in primary biliary cholangitis patients in Europe

\begin{tabular}{llll}
\hline & $\begin{array}{l}\text { Prince } \\
\text { et al. [15] }\end{array}$ & $\begin{array}{l}\text { Floreani } \\
\text { et al. [14] }\end{array}$ & $\begin{array}{l}\text { Boonstra } \\
\text { et al. [36] }\end{array}$ \\
\hline No. of patients & 770 & 327 & 997 \\
Follow-up (years) & $0-28$ & $0.5-26$ & $0-36$ \\
Sex ratio (female/male) & $9: 1$ & $9.5: 1$ & $8.7: 1$ \\
Age at death (years) & NA & $67.2 \pm 1.3$ & NA \\
Liver transplant rate (\%) & 2.4 & 2.7 & 2 \\
$\begin{array}{l}\text { Rate of death from liver } \\
\text { failure, including HCC (\%) }\end{array}$ & 36.1 & 74.9 & 34.4 \\
\hline
\end{tabular}

$H C C$ hepatocellular carcinoma, $N A$ not available

extrahepatic tumors $[37,38]$. One condition that deserves special attention for the increased risk of death is metabolic syndrome, which is common in the general population [39]. Approximately $30 \%$ of patients with PBC may have metabolic syndrome, which, consequently, is correlated with a higher risk of cardiovascular events in the follow-up [40]. In a long-term follow-up of an Italian cohort of PBC patients, metabolic syndrome has not been shown to represent an additional risk factor for death [41]; however, this aspect should be carefully evaluated in old PBC patients, PDC patients with high cholesterol levels associated with low HDL concentration, or PBC patients who do not respond to UDCA.

A study using multiple cause of death files that comprise all death certificates issued in the USA between 1980 and 1998 reported the mortality attributable to cholestatic liver disease [42]. During the observation period, PBC-related mortality decreased over time in women younger than 65 years and in men of all age groups, whereas in older women, PBC-related mortality increased over time [42]. The most noticeable change was an increase in the age of death, suggesting increased survival. The study authors attribute these changes in mortality to liver transplant or UDCA therapy. In contrast, the increased mortality in older women with $\mathrm{PBC}$ was attributable to the fact that those treatment modalities were not curative.

A recent article examined the administrative data of the inpatient population in Lombardia, a northern Italian province with a population of 9.7 million, and Denmark, with a population of about 5.5 million, using the Danish National Patient Registry [43]. In Lombardia there were 2970 PBC cases, with a female-to-male ratio of 2.3:1, and in Denmark there were 722 cases of incident PBC, with a female-to-male ratio of 4.2:1. Surprisingly, both of these sex ratios were lower than previously cited; moreover, this report identified a surprisingly higher overall mortality for male patients [43].

It is well known that PBC is closely associated with an increased risk of HCC [41]. A recent study conducted by 
the Global PBC Study Group in more than 15 centers fin North America and Europe found that in PBC, males with advanced liver disease develop HCC more frequently [44]. The role of male sex in the development of HCC in PBC has also been found in a representative cohort of Chinese and Japanese patients with a long follow-up [45, 46]. A large cohort of 1865 well-defined Chinese patients with PBC were evaluated for the incidence of HCC up to 20 years. HCC occurred in less than $5 \%$ of patients, but the risk was significantly increased by increased age, male sex, diabetes mellitus, and previous hepatitis B virus infection [46]. In another large cohort in Japan, the HCC incidence was $2.4 \%(71 / 2946)$, and male sex and advanced histological stage in females are independent risk factors for the development of HCC in patients with PBC [45].

\section{Predictors of outcome}

A number of factors potentially influencing PBC outcome have been identified:

- Age at diagnosis

- Sex

- Antinuclear specific autoantibodies

- Biochemical markers of fibrosis

- Liver stiffness

- Cirrhosis/portal hypertension

\section{Age at diagnosis}

The reports dealing with prognosis and younger age are scarce and confounding. However, a recent cross-sectional study using the UK PBC cohort including 2353 patients showed that the rate of response to UDCA was less than $50 \%$ for those younger than 30 years [47]. One potential explanation suggested by the study authors is that estrogens can cause resistance to treatment [47]. There are no convincing data on the effect of sex hormones, particularly estrogens, on the impact of therapy in PBC.

\section{Sex}

The more recent data stress the importance of sex for prognosis, particularly the risk of HCC and mortality revealed by administrative data. However, data on sex and prognosis are expected to be confirmed also by ongoing international studies.

\section{Antinuclear specific autoantibodies}

Anti-glycoprotein 120 (anti-gp210) is a subtype of antinuclear antibody directed against the nuclear pore complex.
A retrospective/prospective Japanese cohort study to assess the significance of antinuclear antibodies for progression of PBC found that anti-gp210 antibodies are the strongest antinuclear antibody predictor for progression to end-stage hepatic failure (odds ratio $33.777,95 \%$ confidence interval 5.930-636.745), and the frequency of death was significantly higher in patients positive for anti-gp210 than in those negative for anti-gp210 [48]. However, an additional study including 170 patients from Barcelona and 162 from Greece confirmed that anti-gp210 is a biomarker of severity, but more caution was advised in considering antigp-210 as a marker of disease progression [49].

Anti-centromere antibodies, originally described in patients with systemic sclerosis, can be detected in 10-30\% of patients with PBC. They can be detected before the onset of $\mathrm{PBC}$, and are associated with a high risk of progression to cirrhosis and portal hypertension [48].

\section{Biochemical markers of fibrosis}

A number of noninvasive tests for assessment of liver fibrosis have been assessed in different types of liver disease, including PBC. Attempts have been made to compare the noninvasive markers with the gold standard of histological evaluation or with transient elastography [50-53] (Table 4).

\section{Liver stiffness}

Transient elastography has been proposed and validated for measuring liver fibrosis, initially by the monitoring of patients with chronic hepatitis C. Corpechot et al. [54] assessed the diagnostic performance of transient elastography in 73 patients with $\mathrm{PBC}$ and 28 patients with primary sclerosing cholangitis. Liver stiffness measurements were compared with liver biopsy staging and serum hyaluronic acid levels. The results demonstrated the accuracy and simplicity of transient elastography in the assessment of liver fibrosis. In a subsequent study including 150 patients with PBC who underwent repeated examinations with transient elastography, it was demonstrated that a cutoff value of $2.1 \mathrm{kPa} /$ year was associated with an 8.4-fold increased risk of liver decompensation, liver transplant, or death [55]. In another study, conducted in Spain in 80 patients with $\mathrm{PBC}$, transient elastography showed a significant correlation with liver biopsies [56]. Vibrationcontrolled transient elastography (VCTE) is a technique based on shear-wave propagation that can be generated within tissues. The performance of VCTE has been recently assessed in 44 patients with $\mathrm{PBC}$ for hepatic and splenic elasticity in comparison with real-time tissue elastography [57]. Real-time tissue elastography offered better diagnostic accuracy for severe fibrosis and 
Table 4 Noninvasive markers assessing liver fibrosis in primary biliary cholangitis

\begin{tabular}{|c|c|c|c|c|}
\hline Authors & Test & Type of study & $\begin{array}{l}N . \text { of } \\
\text { patients }\end{array}$ & Comment \\
\hline $\begin{array}{l}\text { Mayo } \\
\text { et al. } \\
\text { [51] }\end{array}$ & ELF assay $^{\mathrm{a}}$ & $\begin{array}{l}\text { Serial biopsy specimens and } \\
\text { blood samples collected }\end{array}$ & 161 & $\begin{array}{l}\text { Better performance of ELF assay in early stages of } \\
\text { disease than MELD and Mayo score }\end{array}$ \\
\hline $\begin{array}{c}\text { Floreani } \\
\text { et al. } \\
{[50]}\end{array}$ & $\begin{array}{l}\text { APRI, FIB-4 score, Fibroindex, } \\
\text { Forns index, AST/ALT ratio }\end{array}$ & Prospective analysis & 120 & $\begin{array}{l}\text { Noninvasive tests unsatisfactory in predicting } \\
\text { significant fibrosis }\end{array}$ \\
\hline $\begin{array}{l}\text { Olmez } \\
\text { et al. } \\
\text { [52] }\end{array}$ & APRI, LFTs, FIB-4 score & Retrospective analysis & 40 & APRI and FIB-4 score predict advanced disease \\
\hline $\begin{array}{l}\text { Stasi et al. } \\
\text { [53] }\end{array}$ & $\begin{array}{l}\text { APRI, Forns index, FIB-4 score, } \\
\text { Lok index }\end{array}$ & Retrospective analysis & 50 & No correlation with fibrosis morphometry \\
\hline
\end{tabular}

cholangitis than VCTE. Moreover, it was shown showed that splenic elasticity determined by real-time tissue elastography may be a predictive marker of disease progression in patients with PBC. Transient elastography is currently under discussion for evaluation of portal hypertension, since good correlation has been reported between liver stiffness values and hepatic venous pressure gradient, as well as the presence of portal hypertension.

\section{Cirrhosis/portal hypertension}

End-stage liver disease is the best parameter predictive of death. In a large Italian cohort of patients followed up for $9.1 \pm 7.7$ years, the cumulative probability of survival over time was $79 \%$ at 10 years, $61 \%$ at 20 years, and $42 \%$ at 25 years [14]. This correlated significantly with the histological stage at the baseline: the probability of survival at 20 years was $82 \%$ for patients with histological stage III, disease $64 \%$ for those with stage III disease, and $42 \%$ for those with stage IV disease $(p=0.0007)$. In the subgroup treated with UDCA, death was significantly associated with the development of esophageal varices [14]. In this context, a noninvasive assessment of esophageal varices using the platelet count to spleen diameter ratio has been proposed as a screening tool for esophageal varices in cirrhotic patients independent of the cause [58].

\section{Conclusion and future directions}

An enormous effort has been made to define the genetics and immuobiology of human autoimmue liver diseases in both human and mouse models [59-72]. Yet there remains an enormous gap between these investigative efforts and clinical translation. The clinical phenotype of PBC differs between patients, and the natural history of the disease can also differ between patients. For example, some patients may have mild elevation of liver enzyme levels and remain asymptomatic for life. By contrast, other patients can develop signs of liver failure and rapidly decompensate despite therapy, requiring liver transplant. It is presumed that these differences are due to genetic and environmental factors, both contributing to the development of PBC to various degrees in each patient. In this regard, more etiology and immunopathology studies using new technologies and novel animal models are needed to dissect the difference in the clinical course, treatment response, and outcome in each patient with PBC. Precision medicine that is individualized for each patient on the basis of the cause identified is eagerly awaited.

\section{Compliance with ethical standards}

Conflict of interest The authors declare that they have no conflict of interest.

\section{References}

1. Poupon R. Primary biliary cirrhosis: a 2010 update. J Hepatol. 2010;52:745-58.

2. Addison, Gull. On a certain affliction of the skin-vitiligoides-a planus tuberosa. Guy's hosp rev. 1857;7:268-274.

3. Ahrens EH Jr, Payne MA, Kunkel HG, Eisenmenger WJ, Blondheim SH. Primary biliary cirrhosis. Medicine (Baltimore). 1950;29:299-364.

4. Sherlock S. Primary billiary cirrhosis (chronic intrahepatic obstructive jaundice). Gastroenterology. 1959;37:574-86.

5. Walker JG, Doniach D, Roitt IM, Sherlock S. Serological tests in diagnosis of primary biliary cirrhosis. Lancet. 1965;1:827-31.

6. Poupon RE, Balkau B, Eschwege E, Poupon R, UDCA-PBC Study Group. A multicenter, controlled trial of ursodiol for the 
treatment of primary biliary cirrhosis. $N$ Engl J Med. 1991;324:1548-54.

7. Nevens F, Andreone P, Mazzella G, Strasser SI, Bowlus C, Invernizzi P, Drenth JP, et al. A placebo-controlled trial of obeticholic acid in primary biliary cholangitis. N Engl J Med. 2016;375:631-43.

8. Hamlyn AN, Sherlock S. The epidemiology of primary biliary cirrhosis: a survey of mortality in England and Wales. Gut. 1974; 15:473-9.

9. Myszor M, James OF. The epidemiology of primary biliary cirrhosis in north-east England: an increasingly common disease? Q J Med. 1990;75:377-85.

10. James OF, Bhopal R, Howel D, Gray J, Burt AD, Metcalf JV. Primary biliary cirrhosis once rare, now common in the United Kingdom? Hepatology. 1999;30:390-4.

11. Metcalf JV, Bhopal RS, Gray J, Howel D, James OF. Incidence and prevalence of primary biliary cirrhosis in the city of Newcastle upon Tyne. England. Int J Epidemiol. 1997;26:830-6.

12. Watson RG, Angus PW, Dewar M, Goss B, Sewell RB, Smallwood RA. Low prevalence of primary biliary cirrhosis in Victoria, Australia. Melbourne Liver Group. Gut. 1995;36:927-30.

13. Sood S, Gow PJ, Christie JM, Angus PW. Epidemiology of primary biliary cirrhosis in Victoria, Australia: high prevalence in migrant populations. Gastroenterology. 2004;127:470-5.

14. Floreani A, Caroli D, Variola A, Rizzotto ER, Antoniazzi S, Chiaramonte M, Cazzagon N, et al. A 35-year follow-up of a large cohort of patients with primary biliary cirrhosis seen at a single centre. Liver Int. 2011;31:361-8.

15. Prince MI, Chetwynd A, Craig WL, Metcalf JV, James OF. Asymptomatic primary biliary cirrhosis: clinical features, prognosis, and symptom progression in a large population based cohort. Gut. 2004;53:865-70.

16. Baldursdottir TR, Bergmann OM, Jonasson JG, Ludviksson BR, Axelsson TA, Bjornsson ES. The epidemiology and natural history of primary biliary cirrhosis: a nationwide population-based study. Eur J Gastroenterol Hepatol. 2012;24:824-30.

17. Myers RP, Shaheen AA, Fong A, Burak KW, Wan A, Swain MG, Hilsden RJ, et al. Epidemiology and natural history of primary biliary cirrhosis in a Canadian health region: a population-based study. Hepatology. 2009;50:1884-92.

18. Pla X, Vergara M, Gil M, Dalmau B, Cistero B, Bella RM, Real J. Incidence, prevalence and clinical course of primary biliary cirrhosis in a Spanish community. Eur J Gastroenterol Hepatol. 2007;19:859-64.

19. Mahl TC, Shockcor W, Boyer JL. Primary biliary cirrhosis: survival of a large cohort of symptomatic and asymptomatic patients followed for 24 years. J Hepatol. 1994;20:707-13.

20. Balasubramaniam K, Grambsch PM, Wiesner RH, Lindor KD, Dickson ER. Diminished survival in asymptomatic primary biliary cirrhosis. A prospective study. Gastroenterology. 1990;98:1567-71.

21. Nyberg A, Loof L. Primary biliary cirrhosis: clinical features and outcome, with special reference to asymptomatic disease. Scand J Gastroenterol. 1989;24:57-64.

22. Springer J, Cauch-Dudek K, O'Rourke K, Wanless IR, Heathcote EJ. Asymptomatic primary biliary cirrhosis: a study of its natural history and prognosis. Am J Gastroenterol. 1999;94:47-53.

23. Beswick DR, Klatskin G, Boyer JL. Asymptomatic primary biliary cirrhosis. A progress report on long-term follow-up and natural history. Gastroenterology. 1985;89:267-71.

24. Roll J, Boyer JL, Barry D, Klatskin G. The prognostic importance of clinical and histologic features in asymptomatic and symptomatic primary biliary cirrhosis. N Engl J Med. 1983;308:1-7.

25. Lindor KD, Gershwin ME, Poupon R, Kaplan M, Bergasa NV, Heathcote EJ. Primary biliary cirrhosis. Hepatology. 2009;50:291-308.
26. Corpechot C, Carrat F, Bahr A, Chretien Y, Poupon RE, Poupon R. The effect of ursodeoxycholic acid therapy on the natural course of primary biliary cirrhosis. Gastroenterology. 2005;128:297-303.

27. Pares A, Caballeria L, Rodes J. Excellent long-term survival in patients with primary biliary cirrhosis and biochemical response to ursodeoxycholic acid. Gastroenterology. 2006;130:715-20.

28. ter Borg PC, Schalm SW, Hansen BE, van Buuren HR. Dutch PBCSG. Prognosis of ursodeoxycholic acid-treated patients with primary biliary cirrhosis. Results of a 10-year cohort study involving 297 patients. Am J Gastroenterol. 2006;101:2044-50.

29. Gong Y, Huang Z, Christensen E, Gluud C. Ursodeoxycholic acid for patients with primary biliary cirrhosis: an updated systematic review and meta-analysis of randomized clinical trials using Bayesian approach as sensitivity analyses. Am J Gastroenterol. 2007;102:1799-807.

30. Lee YM, Kaplan MM. The natural history of PBC: has it changed? Semin Liver Dis. 2005;25:321-6.

31. Lammers WJ, Hirschfield GM, Corpechot C, Nevens F, Lindor $\mathrm{KD}$, Janssen HL, et al. Development and validation of a scoring system to predict outcomes of patients with primary biliary cirrhosis receiving ursodeoxycholic acid therapy. Gastroenterology. 2015;149(7):1804-12

32. Carbone M, Sharp SJ, Flack S, Paximadas D, Spiess K, Adgey C, et al. The UK-PBC risk scores: Derivation and validation of a scoring system for long-term prediction of end-stage liver disease in primary biliary cholangitis. Hepatology. 2016;63:930-50

33. Samur S, Hur C, Klebanoff M, Pratt D, Banken R, Chapman R, Ollendorf D, et al. Long-term clinical outcomes and cost-effectiveness of obeticholic acid for treatment of primary biliary cholangitis. Hepatology. 2017;65(3):920-8. doi:10.1002/hep.28932.

34. Cholankeril G, Perumpail R, Wong R, Yoo E, Hu M, Jayasckera C. Predictors of waitlist outcomes in candidates with primary biliary cholangitis awaiting liver transplantation. Hepatology. 2016; Suppl. 1:(Abst 207).

35. Singal AK, Fang X, Kaif M, Hasanin M, McGuire BM, Kuo YF, Wiesner RH. Primary biliary cirrhosis has high wait-list mortality among patients listed for liver transplantation. Transpl Int. 2016. doi:10.1111/tri.12877.

36. Boonstra K, Bokelaar R, Stadhouders PH, Tuynman HA, Poen AC, van Nieuwkerk KM, Witteman EM, et al. Increased cancer risk in a large population-based cohort of patients with primary biliary cirrhosis: follow-up for up to 36 years. Hepatol Int. 2014;8:266-74.

37. Floreani A, Franceschet I, Cazzagon N, Spinazze A, Buja A, Furlan P, Baldo V, et al. Extrahepatic autoimmune conditions associated with primary biliary cirrhosis. Clin Rev Allergy Immunol. 2015;48:192-7.

38. Floreani A, Spinazze A, Caballeria L, Reig A, Cazzagon N, Franceschet I, Buja A, et al. Extrahepatic malignancies in primary biliary cirrhosis: a comparative study at two European centers. Clin Rev Allergy Immunol. 2015;48:254-62.

39. Vassallo P, Driver SL, Stone NJ. Metabolic syndrome: an evolving clinical construct. Prog Cardiovasc Dis. 2016;59:172-7.

40. Floreani A, Cazzagon N, Franceschet I, Canesso F, Salmaso L, Baldo V. Metabolic syndrome associated with primary biliary cirrhosis. J Clin Gastroenterol. 2015;49:57-60.

41. Liang Y, Yang Z, Zhong R. Primary biliary cirrhosis and cancer risk: a systematic review and meta-analysis. Hepatology. 2012;56:1409-17.

42. Mendes FD, Kim WR, Pedersen R, Therneau T, Lindor KD. Mortality attributable to cholestatic liver disease in the United States. Hepatology. 2008;47:1241-7.

43. Lleo A, Jepsen P, Morenghi E, Carbone M, Moroni L, Battezzati PM, Podda M, et al. Evolving trends in female to male incidence and male mortality of primary biliary cholangitis. Sci Rep. 2016;6:25906. 
44. Trivedi PJ, Lammers WJ, van Buuren HR, Pares A, Floreani A, Janssen HL, Invernizzi P, et al. Stratification of hepatocellular carcinoma risk in primary biliary cirrhosis: a multicentre international study. Gut. 2016;65:321-9.

45. Harada K, Hirohara J, Ueno Y, Nakano T, Kakuda Y, Tsubouchi $\mathrm{H}$, Ichida $\mathrm{T}$, et al. Incidence of and risk factors for hepatocellular carcinoma in primary biliary cirrhosis: national data from Japan. Hepatology. 2013;57:1942-9.

46. Rong G, Wang H, Bowlus CL, Wang C, Lu Y, Zeng Z, Qu J, et al. Incidence and risk factors for hepatocellular carcinoma in primary biliary cirrhosis. Clin Rev Allergy Immunol. 2015;48:132-41.

47. Carbone M, Mells GF, Pells G, Dawwas MF, Newton JL, Heneghan MA, Neuberger JM, et al. Sex and age are determinants of the clinical phenotype of primary biliary cirrhosis and response to ursodeoxycholic acid. Gastroenterology. 2013;144:560-9.

48. Nakamura M, Kondo H, Mori T, Komori A, Matsuyama M, Ito M, Takii Y, et al. Anti-gp210 and anti-centromere antibodies are different risk factors for the progression of primary biliary cirrhosis. Hepatology. 2007;45:118-27.

49. Bogdanos DP, Liaskos C, Pares A, Norman G, Rigopoulou EI, Caballeria L, Dalekos GN, et al. Anti-gp210 antibody mirrors disease severity in primary biliary cirrhosis. Hepatology. 2007;45:1583; author reply 1583-4.

50. Floreani A, Cazzagon N, Martines D, Cavalletto L, Baldo V, Chemello L. Performance and utility of transient elastography and noninvasive markers of liver fibrosis in primary biliary cirrhosis. Dig Liver Dis. 2011;43:887-92.

51. Mayo MJ, Parkes J, Adams-Huet B, Combes B, Mills AS, Markin RS, Rubin R, et al. Prediction of clinical outcomes in primary biliary cirrhosis by serum enhanced liver fibrosis assay. Hepatology. 2008;48:1549-57.

52. Olmez S, Sayar S, Avcioglu U, Tenlik I, Ozaslan E, Koseoglu HT, Altiparmak E. The relationship between liver histology and noninvasive markers in primary biliary cirrhosis. Eur J Gastroenterol Hepatol. 2016;28(7):773-6.

53. Stasi C, Leoncini L, Biagini MR, Arena U, Madiai S, Laffi G, Marra F, et al. Assessment of liver fibrosis in primary biliary cholangitis: comparison between indirect serum markers and fibrosis morphometry. Dig Liver Dis. 2016;48:298-301.

54. Corpechot C, El Naggar A, Poujol-Robert A, Ziol M, Wendum D, Chazouilleres $\mathrm{O}$, de Ledinghen $\mathrm{V}$, et al. Assessment of biliary fibrosis by transient elastography in patients with PBC and PSC. Hepatology. 2006;43:1118-24.

55. Corpechot C, Carrat F, Poujol-Robert A, Gaouar F, Wendum D, Chazouilleres O, Poupon R. Noninvasive elastography-based assessment of liver fibrosis progression and prognosis in primary biliary cirrhosis. Hepatology. 2012;56:198-208.

56. Gomez-Dominguez E, Mendoza J, Garcia-Buey L, Trapero M, Gisbert JP, Jones EA, Moreno-Otero R. Transient elastography to assess hepatic fibrosis in primary biliary cirrhosis. Aliment Pharmacol Ther. 2008;27:441-7.

57. Koizumi Y, Hirooka M, Abe M, Tokumoto Y, Yoshida O, Watanabe T, Nakamura Y, et al. Comparison between real-time tissue elastography and vibration-controlled transient elastography for the assessment of liver fibrosis and disease progression in patients with primary biliary cholangitis. Hepatol Res. 2017. doi:10.1111/hepr.12861.

58. Giannini E, Botta F, Borro P, Risso D, Romagnoli P, Fasoli A, Mele MR, et al. Platelet count/spleen diameter ratio: proposal and validation of a non-invasive parameter to predict the presence of oesophageal varices in patients with liver cirrhosis. Gut. 2003;52:1200-5.

59. Bian Z, Miao Q, Zhong W, Zhang H, Wang Q, Peng Y, Chen X, et al. Treatment of cholestatic fibrosis by altering gene expression of Cthrc1: implications for autoimmune and non-autoimmune liver disease. J Autoimmun. 2015;63:76-87.

60. Hsueh YH, Chang YN, Loh CE, Gershwin ME, Chuang YH. AAV-IL-22 modifies liver chemokine activity and ameliorates portal inflammation in murine autoimmune cholangitis. J Autoimmun. 2016;66:89-97.

61. Hudspeth K, Donadon M, Cimino M, Pontarini E, Tentorio P, Preti M, Hong M, et al. Human liver-resident CD56 $6^{\text {bright }} / C D 16^{\text {neg }}$ NK cells are retained within hepatic sinusoids via the engagement of CCR5 and CXCR6 pathways. J Autoimmun. 2016;66:40-50.

62. Liberal R, Selmi C, Gershwin ME. Diego and Giorgina Vergani: the two hearts of translational autoimmunity. J Autoimmun. 2016;66:1-6.

63. Wang Q, Yang F, Miao Q, Krawitt EL, Gershwin ME, Ma X. The clinical phenotypes of autoimmune hepatitis: a comprehensive review. J Autoimmun. 2016;66:98-107.

64. Wang YH, Yang W, Yang JB, Jia YJ, Tang W, Gershwin ME, Ridgway WM, et al. Systems biologic analysis of $\mathrm{T}$ regulatory cells genetic pathways in murine primary biliary cirrhosis. J Autoimmun. 2015;59:26-37.

65. Yang JB, Wang YH, Yang W, Lu FT, Ma HD, Zhao ZB, Jia YJ, et al. Successful treatment of murine autoimmune cholangitis by parabiosis: implications for hematopoietic therapy. J Autoimmun. 2016;66:108-17.

66. Bae HR, Leung PS, Tsuneyama K, Valencia JC, Hodge DL, Kim $\mathrm{S}$, Back T, et al. Chronic expression of interferon-gamma leads to murine autoimmune cholangitis with a female predominance. Hepatology. 2016;64:1189-201.

67. Hirschfield GM, Gershwin ME, Strauss R, Mayo MJ, Levy C, Zou B, Johanns J, et al. Ustekinumab for patients with primary biliary cholangitis who have an inadequate response to ursodeoxycholic acid: a proof-of-concept study. Hepatology. 2016;64:189-99.

68. Webb GJ, Hirschfield GM. Primary biliary cholangitis in 2016: high-definition PBC: biology, models and therapeutic advances. Nat Rev Gastroenterol Hepatol. 2017;14:76-8.

69. Carbone M, Sharp SJ, Flack S, Paximadas D, Spiess K, Adgey C, Griffiths L, et al. The UK-PBC risk scores: derivation and validation of a scoring system for long-term prediction of end-stage liver disease in primary biliary cholangitis. Hepatology. 2016;63:930-50

70. Hirschfield GM, Siminovitch KA. Genetics in PBC: what do the "risk genes" teach us? Clin Rev Allergy Immunol. 2015;48:176-81.

71. Patanwala I, McMeekin P, Walters R, Mells G, Alexander G, Newton J, Shah $\mathrm{H}$, et al. A validated clinical tool for the prediction of varices in PBC: the Newcastle Varices in PBC Score. J Hepatol. 2013;59:327-35.

72. Liu H, Norman GL, Shums Z, Worman HJ, Krawitt EL, Bizzaro N, Vergani D, et al. PBC screen: an $\mathrm{IgG} / \operatorname{IgA}$ dual isotype ELISA detecting multiple mitochondrial and nuclear autoantibodies specific for primary biliary cirrhosis. J Autoimmun. 2010;35:436-42.

73. Delgado JS, Vodonos A, Delgado B, Jotkowitz A, Rosenthal A, Fich A, Novack V. Primary biliary cirrhosis in southern Israel: a 20 years follow up study. Eur J Intern Med. 2012;23:e193-8.

74. Mahl T, Shockcor W, Boyer J. Primary biliary cirrhosis: survival of a large cohort of symptomatic and asymptomatic patients followed for 24 years. J Hepatol. 1994;20:707-13.

75. Springer J, Cauch-Dudek K, O'Rourke K, Wanless I, Heathcote E. Asymptomatic primary biliary cirrhosis: a study of its natural history and prognosis. Am J Gastroenterol. 1999;94:47-53.

76. Prince M, Chetwynd A, Craig W, Metcalf J, James O. Asymptomatic primary biliary cirrhosis: clinical features, prognosis, and symptom progression in a large population based cohort. Gut. 2004;53:865-70. 